\title{
A role for NRAGE in NF- $\kappa$ B activation through the non-canonical BMP pathway
}

Nicholas Matluk ${ }^{1,2}$, Jennifer A Rochira ${ }^{1,3}$, Aldona Karaczyn ${ }^{1}$, Tamara Adams ${ }^{1}$, Joseph M Verdi ${ }^{{ }^{*}}$

\begin{abstract}
Background: Previous studies have linked neurotrophin receptor-interacting MAGE protein to the bone morphogenic protein signaling pathway and its effect on p38 mediated apoptosis of neural progenitor cells via the XIAP-Tak1-Tab1 complex. Its effect on NF- $\kappa$ B has yet to be explored.

Results: Herein we report that NRAGE, via the same XIAP-Tak1-Tab1 complex, is required for the phosphorylation of IKK $-\alpha / \beta$ and subsequent transcriptional activation of the p65 subunit of NF- $\kappa$ B. Ablation of endogenous NRAGE by siRNA inhibited NF- $\kappa$ B pathway activation, while ablation of Tak1 and Tab1 by morpholino inhibited overexpression of NRAGE from activating NF- $\kappa$ B. Finally, cytokine profiling of an NRAGE over-expressing stable line revealed the expression of macrophage migration inhibitory factor.

Conclusion: Modulation of NRAGE expression revealed novel roles in regulating NF- $\kappa$ B activity in the noncanonical bone morphogenic protein signaling pathway. The expression of macrophage migration inhibitory factor by bone morphogenic protein -4 reveals novel crosstalk between an immune cytokine and a developmental pathway.
\end{abstract}

\section{Background}

The bone morphogenic proteins (BMPs) are a subset of the transforming growth factor $\beta$ (TGF- $\beta$ ) superfamily and function through the dimerization of the BMPR-1a and BMPR-2a serine threonine kinase receptors. The canonical BMP pathway regulates gene expression via SMAD1, 4, 5, and 8 [1] while the non-canonical BMP pathway regulates NF- $\kappa$ B via the XIAP-Tak1-Tab1 complex $[2,3]$. Both pathways help direct proper proliferation and differentiation, embryogenesis and adulthood.

The NF- $\kappa$ B pathway is activated at sites of injury and controls the expression of inflammatory and immune regulating cytokines and chemokines as well as regulating apoptosis and cell cycle. The NF- $\kappa \mathrm{B}$ pathway consists of several transcription factors which are bound as homodimers or heterodimers; p65 (RelA), p50 (NF-kB1), p52 (NF-kB2), RelB, and c-Rel [4,5]. These transcription factors reside in an inactive state in the cytoplasm bound to the $\mathrm{I} \kappa \mathrm{B}$ family of proteins. Activation with various stimuli including but not limited to LPS, flagellin, Lipid A, ssRNA, dsRNA and cytokines causes them

\footnotetext{
* Correspondence: verdij@mmc.org

${ }^{1}$ Maine Medical Center Research Institute, Center for Molecular Medicine, 81 Research Drive, Scarborough, Maine 04074, USA
}

to be translocated to the nucleus $[4,5]$. The canonical NF- $\kappa \mathrm{B}$ pathway requires IKK $\alpha \beta \gamma$ phosphorylation and subsequent degradation of IkB $\alpha$. Previous research has linked the canonical NF- $\kappa \mathrm{B}$ pathway to the non-canonical BMP pathway via the formation of the XIAP-Tab1Tak1 complex [2,3,6-8].

Adapter proteins play a pivotal role in the regulation and function of signal transduction pathways. Activation of NF- $\kappa \mathrm{B}$ pathways through the stimulation of toll-like receptors (TLRs) or interleukin pathways require MyD88, IRAK proteins, and TRAF proteins to propagate the signal from the extracellular matrix to the Tak1Tab1 complex which is responsible for the phosphorylation of IKK- $\alpha / \beta$. The non-canonical BMP pathway also uses the Tak1-Tab1 complex to drive phosphorylation of IKK- $\alpha / \beta$, but uses the ring finger protein XIAP instead of TRAF6 [2,3,6-8]. The similarity of these two pathways suggested that an additional adapter protein could be present linking XIAP-Tak1-Tab1 to the BMPR1a receptor.

A member of the melanoma antigen family, the neurotrophin receptor-interacting MAGE protein (NRAGE) is ubiquitously expressed in tissue and contains a unique WQXPXX hexapeptide repeat domain, suggesting that
Ciomed Central

C 2010 Matluk et al; licensee BioMed Central Ltd. This is an Open Access article distributed under the terms of the Creative Commons Attribution License (http://creativecommons.org/licenses/by/2.0), which permits unrestricted use, distribution, and reproduction in any medium, provided the original work is properly cited. 
NRAGE has a unique function which differs from the other MAGE family of proteins. Previous studies linked NRAGE to XIAP using a yeast two hybrid screen [9] while we have previously identified NRAGE as a critical component in the activation of p38 and subsequent downstream proapoptotic signals via the non-canonical BMP pathway $[10,11]$. Using a similar approach to Kendall et al. in which the expression of NRAGE was modulated through a series of loss of function and gain of function experiments, we have found that NRAGE is also a required component in driving NF- $\kappa \mathrm{B}$ activation through the BMPR1a-XIAP-Tak1-Tab1 complex in 293HEK cells.

\section{Results}

NRAGE is required for NF- $\kappa$ B activation in the noncanonical BMP-4

Previous reports linked NRAGE to the XIAP-Tab1-Tak1 complex and phosphorylation of p38 [10,11]. We wanted to determine if NRAGE was also required for the activation of NF- $\kappa \mathrm{B}$ through the non-canonical BMP pathway. Overexpression of full length NRAGE in
293HEK cells resulted in the constitutive phosphorylation of IKK- $\alpha$ and IKK- $\beta$ (Figure 1A) while disruption of NRAGE expression through siRNA resulted in the inhibition of IKK- $\alpha / \beta$ phosphorylation (Figure 1A). When compared to cells transfected with control siRNA, the NRAGE siRNA transfected cells showed an ablation in transcriptional activation of the p65 subunit of NF- $\kappa \mathrm{B}$ after treatment with BMP-4 (Figure 1B). Stimulation with BMP-4 or transfection with NRAGE resulted in translocation of p65 to the nucleus as verified by immunofluorescence (Figure 1C). Transfection of 293HEK cells with NRAGE siRNA prior to stimulation with BMP-4 abrogated this effect as p65 was still found sequestered in the cytoplasm (Figure 1C).

To ensure that the activity of NRAGE on the NF- $\kappa \mathrm{B}$ pathway was specific to the non-canonical BMP pathway, the inhibitor IKK-VII was used to eliminate the phosphorylation of IKK- $\alpha$ and IKK- $\beta$ and IKK- $\gamma$ and subsequent ubiquitination of $\mathrm{I} \kappa \mathrm{B} \alpha$. IKK-VII is a concentration dependent specific ATP competitive inhibitor of IKK proteins. Inhibition of the IKK proteins resulted in a decrease in p65 transcriptional activity in the NRAGE
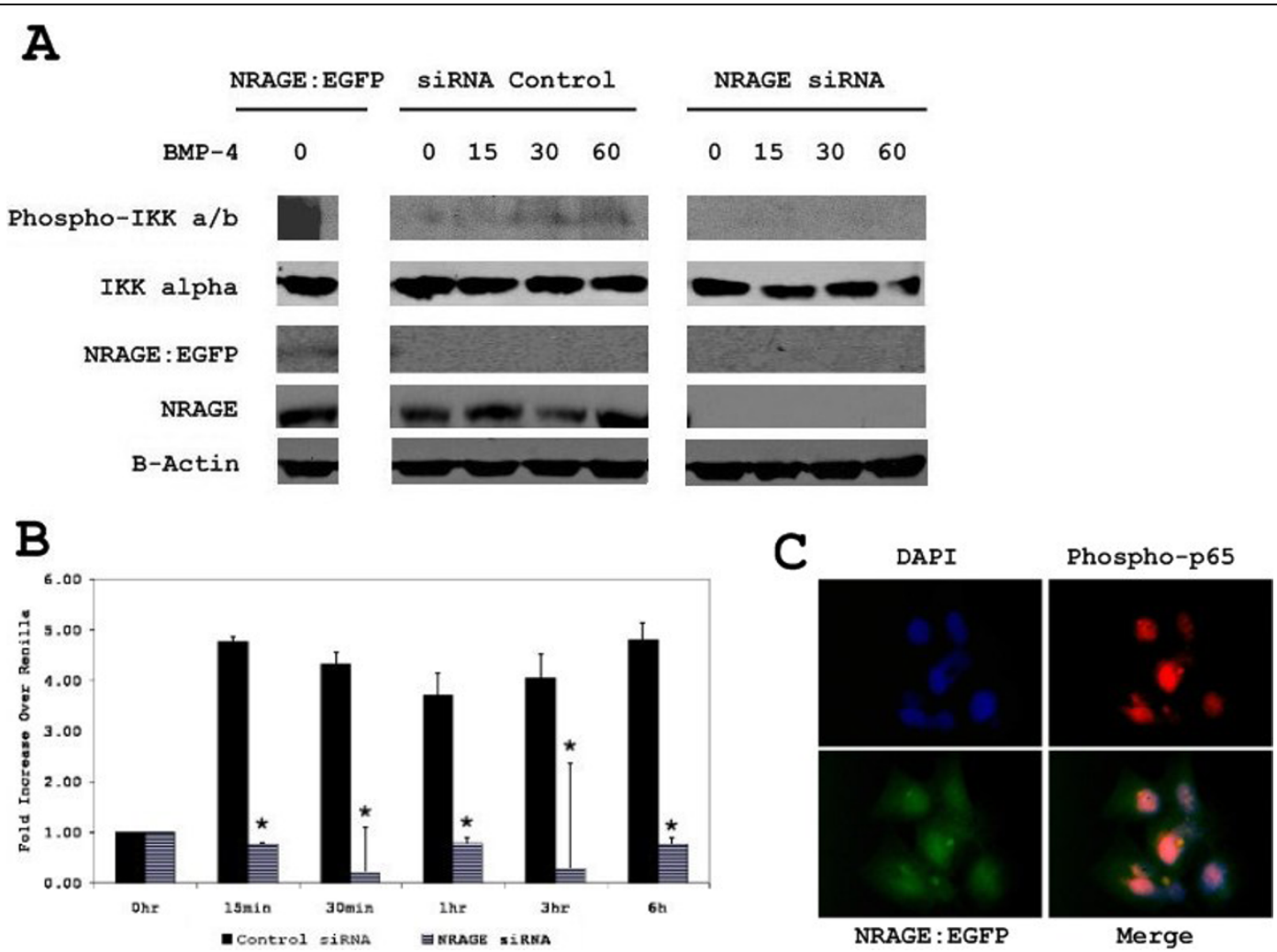

Figure 1 Activation of the NF- $\kappa$ B pathway requires NRAGE in the BMP-4 pathway. A: A total of 293 cells were transfected with NRAGE: EGFP, NRAGE siRNA or a control vector, stimulated with $10 \mathrm{ng} / \mathrm{ml} \mathrm{BMP-4}$ for 15,30 and 60 minutes, and western blotted for NRAGE, phosphoIKK $\alpha / \beta$ and total IKK $\alpha$. B: A total of 293 cells were transfected with NRAGE siRNA or a control siRNA, stimulated with $10 \mathrm{ng} / \mathrm{nl}$ BMP-4, and activation assessed by luciferase assay. Luciferase assays were performed in triplicate and presented as fold increase over renilla. $\mathbf{C}$ : Immunofluorescence of phospho-p65 in the NRAGE:EGFP stable line. Magnification at 40x. ${ }^{*} P<0.05$; siRNA control by the two-tailed unpaired Student's $t$ test 
transfected cells (Figure 2A). Stimulation of GFP transfected with BMP-4 served as an internal control (Figure 2A).

Previous work has shown that a Tak1 or Tab1 morpholino is sufficient for ablation of p38 activity in cells overexpressing NRAGE $[10,11]$. Similar to this, we found that NF- $\kappa \mathrm{B}$ transcriptional activation (Figure $2 \mathrm{~B}$ ) and IKK- $\alpha / \beta$ phosphorylation (Figure $2 \mathrm{C}$ ) were ablated in 293HEK cells overexpressing NRAGE when treated with Tak1 or Tab1 morpholinos for 48 hours. Figure $2 \mathrm{C}$ depicts endogenous phospho-IKK- $\alpha$ and phospho-IKK- $\beta$ after stimulation with BMP-4 and after incubation with Tak1 or Tab1 morpholinos for 48 hours.

Immunoprecipitation studies using rabbit anti GFP to purify protein complexes involving NRAGE revealed that phospho-IKK- $\alpha$ and phospho-IKK- $\beta$ are bound upon overexpression of NRAGE:GFP fusion protein
(Figure 2D). Incubation of NRAGE:GFP transfected cells with either Tak1 or Tab1 morpholinos for 72 hours prevented the formation of the phospho-IKK- $\alpha / \beta$ and NRAGE complex (Figure 2D). The efficiency of Tak1 and Tab1 morpholinos are shown in Figure 2E.

Overexpression of NRAGE results in the expression of macrophage migration inhibitory factor

Although a primary result of non-canonical BMP signaling is apoptosis, we surmise that there is an anti-apoptotic component to this pathway since there is a niche of neural stem cells in the adult brain despite BMP induced apoptosis of neural stem cells during development [12-14]. Analysis of 293HEK cells stably transfected with either GFP or the adapter protein NRAGE: GFP using the Human Cytokine Protein Array (R\&D Systems, Minneapolis, Minnesota, United States, Cat: ARY005), revealed that macrophage migration inhibitory

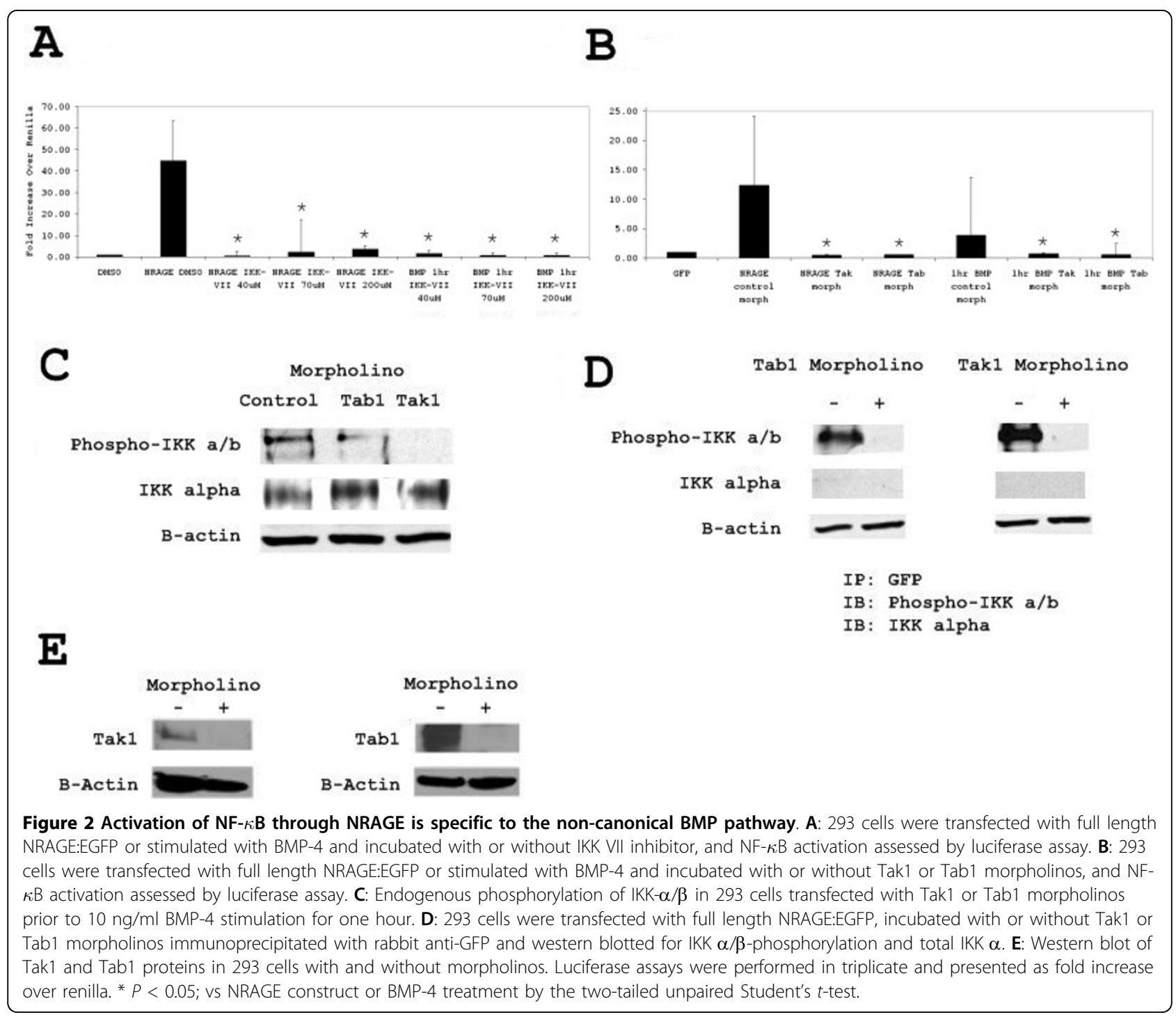


factor (MIF) was highly expressed (square box Figure 3A). Analysis of the 293HEK EGFP stable line stimulated with and without BMP-4 was used to determine endogenous expression of MIF (Figure 3B, Lane 2 and 3). MIF expression of the 293HEK NRAGE:EGFP stable line is shown in lane 1 of Figure 3B. Ablation of MIF expression occurred when Tak1 morpholino was added, prior to BMP stimulation (Figure 3B, Lane 4 and 5) and when NF- $\kappa$ B inhibitor was added prior to BMP-4 stimulation (Figure 3B, Lane 6 and 7).

\section{Overexpression of NRAGE in the mouse kidney}

Next, we used mice overexpressing a NRAGE:Cherry fusion protein in the kidney under the control of the HoxB7 promoter, to determine if NF- $\kappa \mathrm{B}$ would be constitutively active in vivo. Histological analysis revealed that there was constitutive phosphorylation of IKK- $\alpha / \beta$ (Figure 4B) and translocation p65 to the nucleus (Figure
4C, 4K-4O) in the NRAGE:Cherry transgenic mouse. There was no detected phosphorylation of either IKK- $\alpha$ / $\beta$ in the wild type kidneys (Figure 4G) or nuclear translocation of the p65 subunit of NF- $\kappa$ B (Figure 4H). Histological analysis of the kidney from the overexpressing NRAGE:Cherry transgenic mouse revealed that there was a dramatic increase in MIF expression detected by Alexa Flour 488 (Figure 4D), as compared to the wildtype kidney (Figure 4I). In vivo overexpression of NRAGE does not result in the influx of inflammatory cells (Figure 4E and 4J) as seen by hematoxylin and eosin staining.

\section{NRAGE induces NF- $\kappa$ B activation and MIF expression in} P19 cells

Experiments were conducted in P19 cells to demonstrate that the results obtained using 293 cells are physiologically relevant. Overexpression of full length

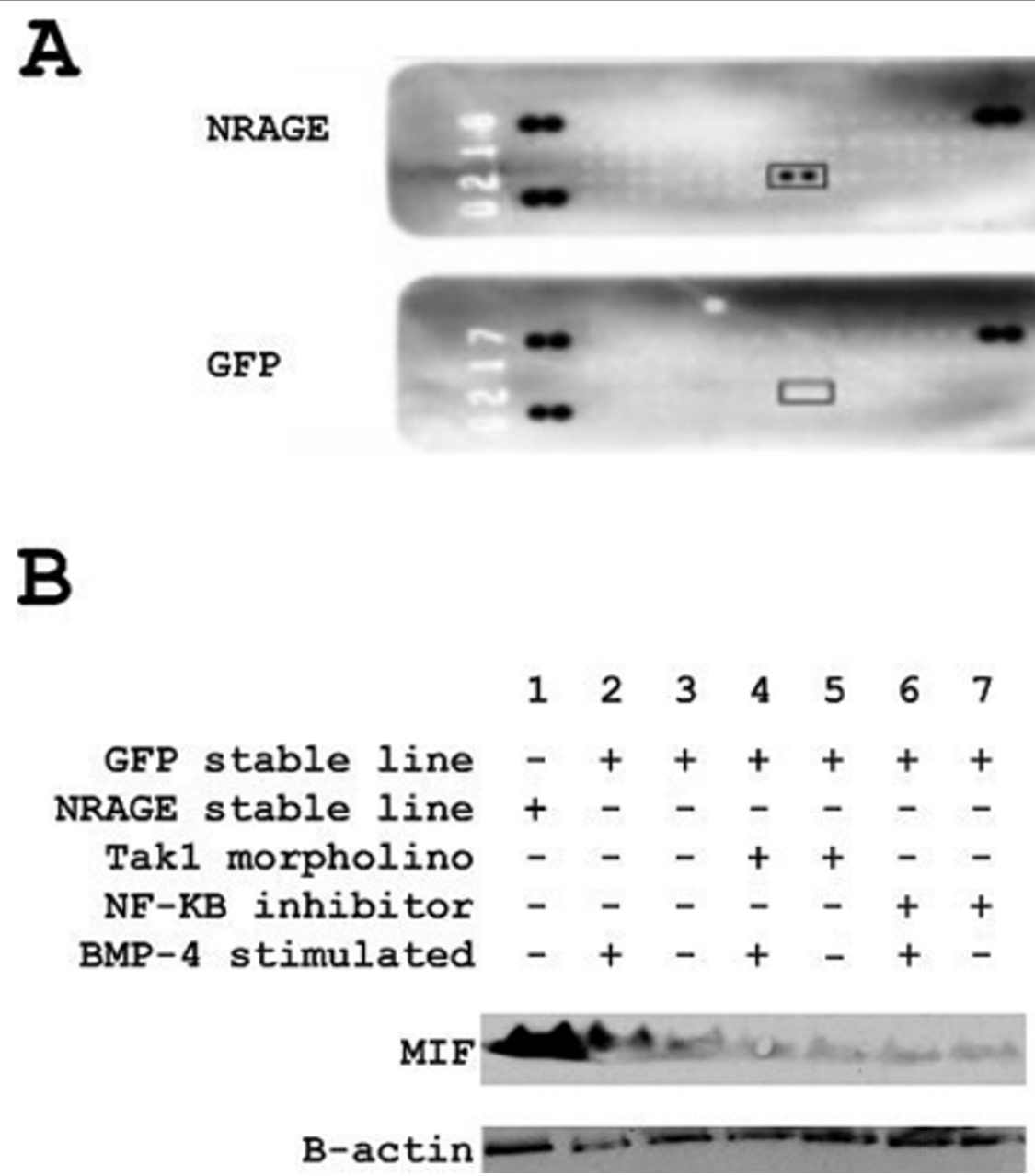

Figure 3 BMP-4 induces the expression of MIF. A: Dot blot array for the secretion of cytokines and chemokines induced by NRAGE overexpression in $293 \mathrm{HEK}$ cells. Squared area indicates duplicate MIF blotting. B: Qualification of macrophage migrating inhibitory factor expression by western blot in 293HEK cells. MIF expression is induced after 24 hours stimulation with $10 \mathrm{ng} / \mathrm{ml}$ BMP-4 or NRAGE overexpression, and is inhibited by Tak morpholino and NF- $\kappa$ B inhibitor. 


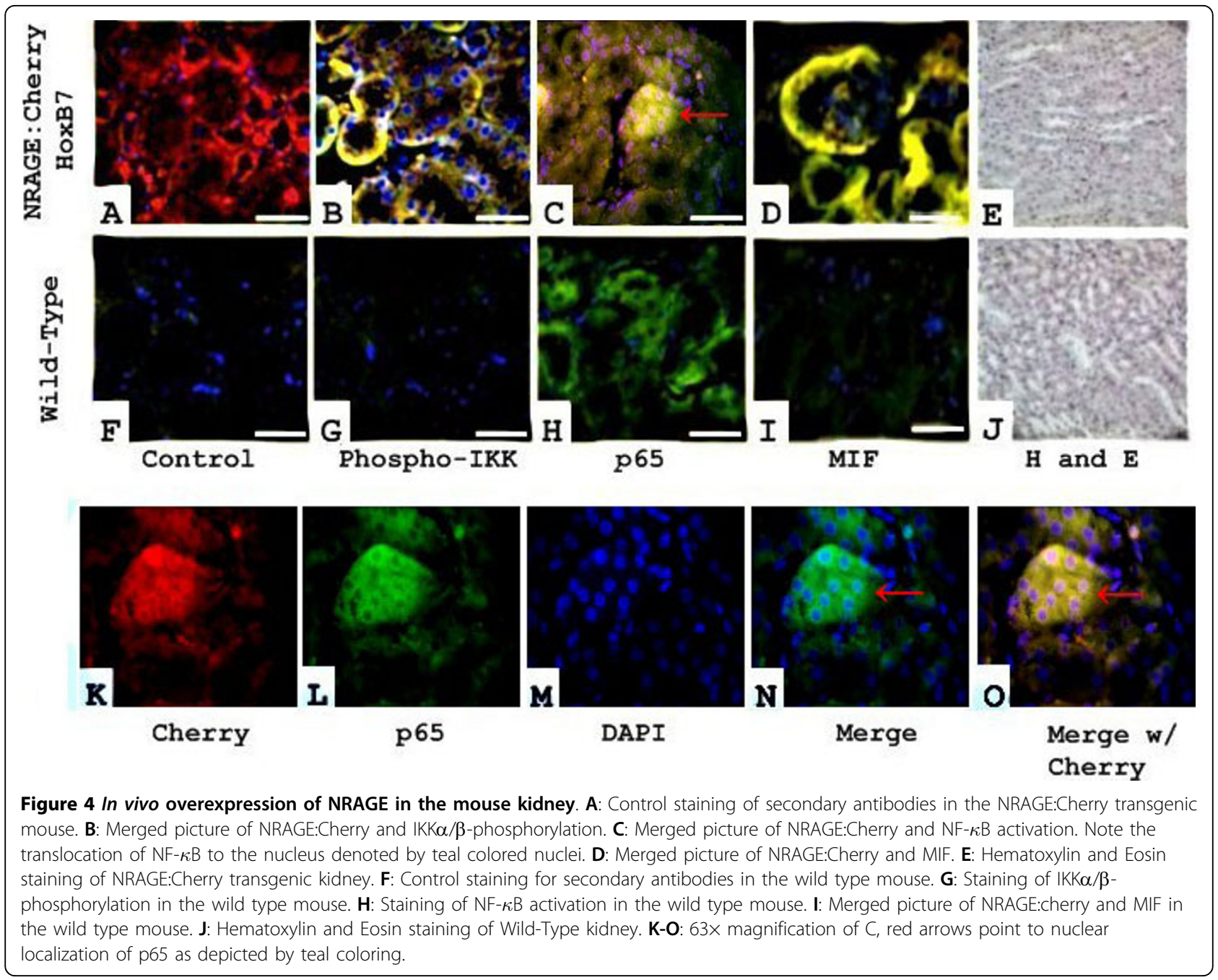

NRAGE in P19 cells resulted in the constitutive phosphorylation of IKK- $\alpha / \beta$ while disruption of NRAGE expression through siRNA resulted in the inhibition of IKK- $\alpha / \beta$ phosphorylation (Figure $5 \mathrm{~A}$ ). Transfection of P19 cells with NRAGE, renilla and a NF- $\kappa$ B-luciferase reporter vector showed transcriptional activation of the p65 subunit of NF- $\kappa$ B (Figure $5 B$ ). Ablation of NRAGE expression with the NRAGE siRNA disrupted NF- $\kappa \mathrm{B}$ transcriptional activity ( $P$-value of 0.027$)$. IKK- $\alpha / \beta$ phosphorylation and luciferase expression were ablated when NRAGE siRNA was transfected prior to BMP-4 stimulation. As was seen in Figure 3B, BMP-4 stimulation or NRAGE transfection resulted in an increase in MIF expression (Figure 5C).

\section{Discussion}

Stimulation of cells with BMP-4 activates the canonical and non-canonical BMP pathways. Signal transduction through the canonical pathway utilizes SMAD proteins, while the non-canonical pathway utilizes XIAP-Tab1-
Tak1, ultimately using the kinase activity of Tak1 to activate the $\mathrm{p} 38$, JNK, and NF- $\kappa \mathrm{B}$ pathway. Signal transduction of NF- $\kappa \mathrm{B}$ through the non-canonical BMP pathway is similar to the toll-like receptor pathways and interleukin-1 pathway which require the formation of TRAF6-Tab1-Tak1. Both TRAF6 and XIAP are ring finger proteins which dimerize and consist of three baculovirus IAP repeat domains required for proper orientation of the Tab1-Tak1 complex. The difference is that the TLR and IL-1 pathways also utilize several adapter molecules linking the TRAF6-Tab1-Tak1 complex to their membrane bound receptors such as, Tram, Tirap, MyD88, and IRAK [4,5]. Because NRAGE has already been identified as an adapter protein for p38 signaling through the non-canonical BMP pathway, we thought it feasible that NRAGE also plays a role in NF$\kappa \mathrm{B}$ signaling.

Experiments in which cells were transfected with a full length NRAGE expression vector illustrated that IKK $\alpha \beta$ became phosphorylated (Figure 1A), induced luciferase 


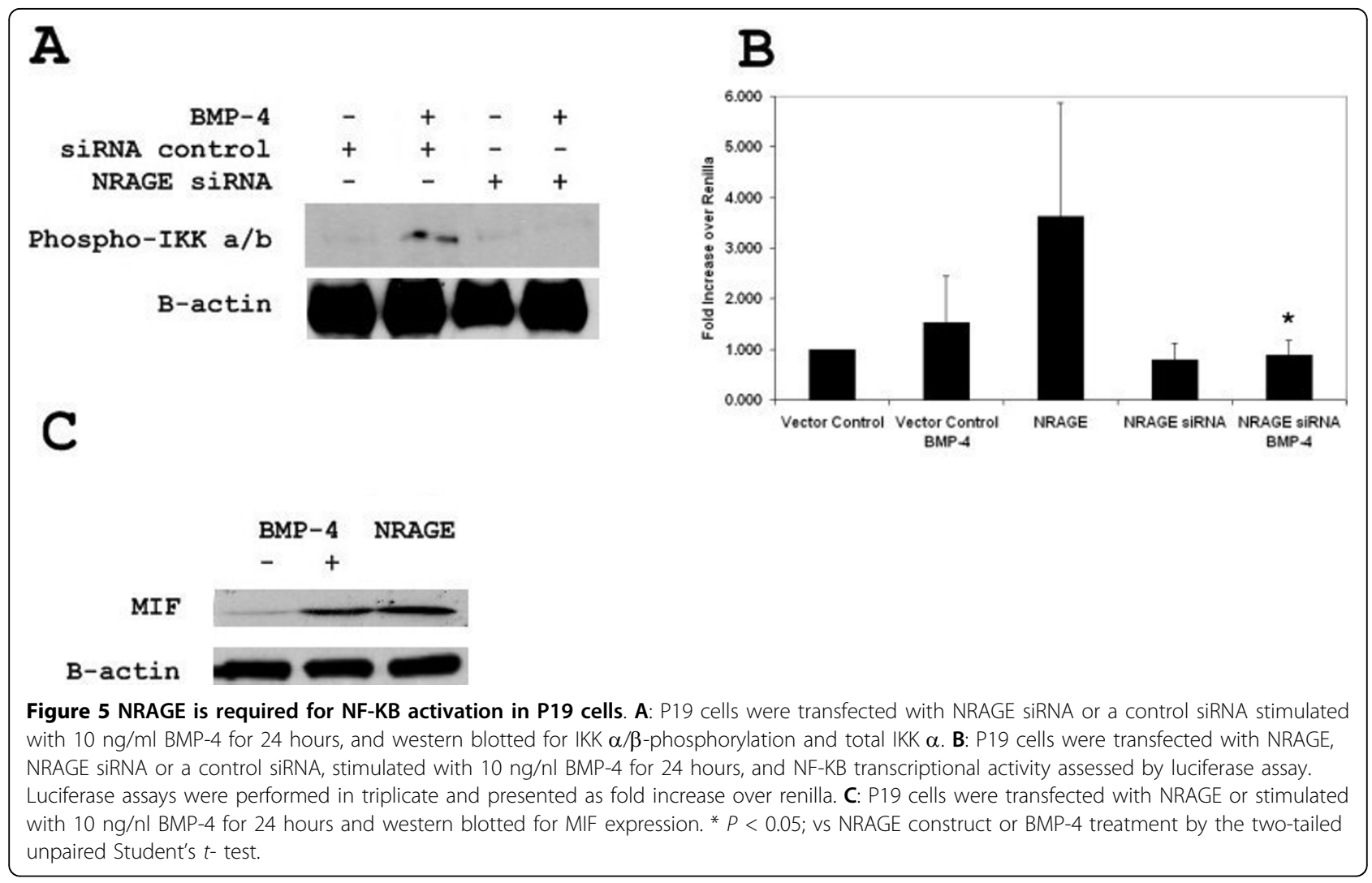

expression (Figure 2A and 2B) and p65 translocated to the nucleus (Figure 1C). Experiments in which the expression of NRAGE, Tab1, or Tak1 were reduced, either by siRNA or morpholino showed that all three proteins were required for NF- $\kappa \mathrm{B}$ pathway activation (Figures 1A, B and 2B, C, D). It was also found that despite overexpression of NRAGE, silencing of Tab1 or Tak1 inhibited NF- $\kappa$ B activation (Figure $2 \mathrm{~A}$ ), showing that a reduction in downstream kinase protein concentration is able to overcome an increase in upstream protein concentration. Immunoprecipitation of the activated non-canonical BMP complex revealed that NRAGE and phosphorylated IKK $\alpha / \beta$ but not IKK $\alpha$ are indirectly bound through Tab1 and Tak1 (Figure 2D).

Taken together, these observations support a mandatory role for NRAGE in NF- $\kappa \mathrm{B}$ signalling through the non-canonical BMP pathway.

Tak1 is the functional kinase in the non-canonical BMP pathway as well as in interleukin, toll-like receptor and TGF- $\beta$ signaling pathways; responsible for the phosphorylation and activation of $\mathrm{p} 38, \mathrm{NF}-\kappa \mathrm{B}$, and JNK, and is found complexed together in the cytoplasm with Tab1. Figure $2 \mathrm{C}$ shows that siRNA knockdown of Tak1 but not Tab1 results in complete inhibition of IKK $\alpha / \beta$ phosphorylation. This observation is similar to experiments by Shim et al., which show that NF- $\kappa$ B activation in embryonic fibroblasts from Tak1 -/- mice but not Tab1 -/- and Tab2 -/- mice is perturbed. It is known that Tab2 and Tab3 also associate with Tak1 and Tab1 to regulate the classical NF- $\kappa \mathrm{B}$ pathway. Redundancy in function or protein:protein interactions may compensate for the loss or inactivation of one or more of the Tab proteins.

It is interesting to note that NRAGE influences both apoptosis and NF- $\kappa \mathrm{B}$ signaling through two distinct mechanisms in two different pathways. In the non-canonical BMP pathway, NRAGE binds XIAP, sequestering it to the cell membrane resulting in the activation of MAPK and NF- $\kappa$ B. While in response to DNA damage, NRAGE prevents the expression of XIAP via NF- $\kappa$ B by sequestering Che- 1 in the cytoplasm where it is targeted for ubiquitination and degradation $[15,16]$. Does this constitute an intrinsic link between NRAGE/XIAP/NF$\kappa \mathrm{B}$ and apoptosis? And if so will NRAGE be found to regulate other NF- $\kappa \mathrm{B}$ pathways such as the toll-like receptors where XIAP is upregulated upon TLR-4 stimulation [17]?

Protein array analysis of secreted cytokines from the NRAGE:EGFP stable line revealed that macrophage migration inhibitory factor (MIF) was highly expressed (Figure 3A) and western blot of protein lysates confirmed MIF expression in the cytoplasm. Stimulation of 
the EGFP stable line with BMP-4 for 24 hours revealed that MIF expression is specific to the BMP pathway, while ablation of Tak1 detail that MIF is being induced through the non-canonical BMP pathway (Figure 3B). The MIF promoter contains two NF- $\kappa \mathrm{B}$ binding sites, located at positions $-2538 /-2528 \mathrm{bp}$ and $-1389 /-1380 \mathrm{bp}$ [18], inhibition of IKK prior to BMP-4 stimulation prevented the expression of MIF (Figure 3B).

Classical research into MIF has focused on its regulatory role of immune system [19]. Recent findings though indicate that MIF can control the cell cycle through interactions with JAB1 and p27 ${ }^{\mathrm{KIP} 1}$ [20], control proliferation [19], and inhibit apoptosis through the stabilization of p53 and Mdm2 [21,22]. Constitutive activation of the BMP pathway [23-26] and the expression of MIF [27-30] have been linked to a variety of cancers.

The BMP pathway is required for proper kidney development and function and injury repair [31-35]. MIF is constitutively expressed in the kidney [36] and is upregulated in chronic kidney disease, glomerulonephritis, and oxidative stress [37-40]. Nikopoulos et al. used transgenic mice in which a NRAGE:Cherry fusion protein is under control of the HoxB7 promoter and results in constitutive phosphorylation of $\mathrm{p} 38^{\mathrm{MAPK}}$ in the kidney through the non-canonical BMP signaling pathway [11]. Our immunohistological analysis of these transgenic kidneys revealed that there was also constitutive activation of the NF- $\kappa \mathrm{B}$ pathway (Figure $4 \mathrm{~B}-\mathrm{C}$ ) and an increase in MIF expression (Figure 4D). It would be interesting to determine if BMP induces MIF expression in response to both renal development and injury, counteracting BMP induced renal apoptosis.

BMP expression is present in neural stem cell migratory pathways and the neural crest during embryogenesis, controlling neural crest differentiation and apoptosis in the hindbrain. On mouse embryonic Day 13 , when corticogenesis begins, BMP-2 and 4 expression are dramatically increased, affecting neural stem cells in the ventricular zone, inhibiting their proliferation through apoptosis [41-43]. Eventually, two neural stem cell niches are established having escaped BMP induced apoptosis; one in the subventricular zone (SVZ) and one in the subgranular zone (SGZ). We used the mouse embryonic carcinoma P19 cell line a model for BMP induced apoptosis in neural stem cells [44], to illustrate that the BMP NRAGE NF- $\kappa \mathrm{B}$ link is not just restricted to 293HEK cells (Figure 5). With the novel finding that MIF expression can be linked to BMP signaling and that MIF is expressed during embryogenesis [45-48], it is imperative that the correlation between the anti-apoptotic cytokine MIF and BMP driven apoptosis be elucidated.

\section{Conclusion}

The finding that NRAGE regulates NF- $\kappa \mathrm{B}$ signaling in the non-canonical BMP pathway adds an extra level of control to an already highly regulated developmental pathway. The observation that stimulation of the noncanonical BMP pathway results in MIF expression, represents novel crosstalk between a classical immune cytokine and a developmental pathway which requires future consideration.

\section{Methods}

\section{Cell culture and transfection}

293HEK cells were cultured in DMEM:F12 media supplemented with $10 \% \mathrm{FBS}$, gentamycin at $37^{\circ} \mathrm{C} 5 \% \mathrm{CO}_{2}$. Cells were trypsinized and passaged at $75 \%$ confluency. Genejuice (EMDBiosciences, Darmstadt, Germany) was used per manufacturers' instructions for the transfection of plasmids into 293HEK cells and Endoporter (GeneTools, Philomath, OR, USA) was used per manufacturer's instructions for the transfection of morpholinos. Cells transfected with siRNA, shRNA or morpholinos were cultured for at least 48 hours prior to analysis. Cells were exposed to IKK-VII (EMDBiosciences, Cat. 410486) at varying concentrations throughout the entire procedure to inhibit NF- $\kappa \mathrm{B}$ activation. In all experiments, cells were serum starved for approximately four hours prior to the addition of $10 \mathrm{ng} / \mathrm{ml}$ of BMP-4 (R\&D Systems, Minneapolis, MN, USA).

\section{Plasmids and morpholinos}

Full length NRAGE was cloned into the mammalian expression vector pEGFP-N3 (Clonetech, Mountain View, CA, USA, Cat. PT3052-5). The pEGFP-N3 vector codes of the neomycin resistance gene and was used to aid in the creation of a NRAGE:EGFP stable line. NRAGE siRNA Sense GGCUUGGAAUGACACUACUtt and Anti Sense AGUAGUGUCAUUCCAAGCCtt (Ambion, Austin, TX, USA) were cloned into psuppressor.retro (Imgenex, San Diego, CA, USA). Control siRNA \#1 was supplied by Ambion (Cat. 4611). The following morpholinos were used: NRAGE morpholino GGTTTCTGAGCCATAGCTCTCGTC (Gene-Tools), Tak1 morpholino AGCGCCCTTCAGCCCGGAGCCC (Gene-Tools), Tab1 morpholino CAGGCTCCTCCTCTGCGCCGCCATC (Gene-Tools), Control morpholino CCTCTTACCTCAGTTACAATTTATA (Gene-Tools).

\section{Western blotting and immunoprecipitation}

Cells were serum starved for approximately four hours prior to the addition of $10 \mathrm{ng} / \mathrm{ml}$ of BMP-4 (R\&D Systems) or cells were transfected with respective vectors for 24 hours prior to being lysed with either RIPA buffer or NP-40 buffer supplemented with tyrosine phosphatase inhibitors (Upstate, Billerica, MA, USA, Cat. 20- 
203), Ser/Thr phosphatase inhibitors (Upstate, Cat.20204) and Protease Inhibitor Cocktail Set III (Calbiochem, Darmstadt, Germany, Cat. 539134). Lysates were then centrifuged at $10,000 \mathrm{rpm}$ and the supernatant stored at $-80^{\circ} \mathrm{C}$ until use. Protein concentration was obtained via Pierce BCA Kit (Rockford, IL, USA, Cat. 23235) per manufacturer's instructions. Western blotting and immunoprecipitation were performed as previously described [44]. The following antibodies were used for western blotting: rabbit anti-phospho-IKK $\alpha / \beta$ (Cell Signaling, Danvers, MA, USA, Cat. 2078) (1:1000 dilution), rabbit anti-IKK $\alpha$ (Cell Signaling, Cat. 2682) mouse anti $\beta$-actin (Novus, Littleton, CO, USA, Cat. NB 600-501) (1:10000 dilution), mouse anti-Tak1 (Santa Cruz, Santa Cruz, CA, USA, Cat. sc-7967) (1:1000 dilution), goat anti-Tab1 (Santa Cruz, Cat. sc-6052) (1:1000 dilution), goat anti-NRAGE (Santa Cruz, Cat. sc-14400 and sc14398) (1:500 dilution), rabbit anti-GFP (Santa Cruz, Cat. sc-8334) (1:1000 dilution), and rabbit anti-MIF (Santa Cruz, Cat. sc-20121) (1:1000 dilution). The following secondary antibodies were all diluted to 1:3000; goat anti-rabbit HRP (Bio-Rad, Hercules, CA, USA, Cat. 170-6515), goat anti-mouse HRP (Bio-Rad, Cat. 1706516), and donkey anti-goat HRP (Santa Cruz, Cat. sc2020). Analysis of cytokine expression on the EGFP and NRAGE:EGFP stable line using the Human Cytokine Protein Array (R\&D Systems, Cat: ARY005) was performed as per manufacturer's instructions.

\section{Luciferase assay}

293HEK cells in a $100 \mathrm{~mm}$ dish were first transfected with NF- $\kappa$ B luciferase (Stratagene, LaJolla, CA, USA, Cat. 219078-51) and Renilla via Genejuice (EMDBiosciences). These cells were then trypsinized, counted and plated at a density of 30,000 cells/well in 24 well culture plates, prior to transfection with various plasmids using Genejuice. The Dual Luciferase Assay Kit (Promega, Madison, WI, USA, Cat. E1980) was used for the analysis of NF $-\kappa \mathrm{B}$ activation. All data are presented as a fold increase over renilla activity and were performed in triplicate.

\section{Immunohistochemistry}

Six-month-old wild type and NRAGE:Cherry HoxB7 mice were euthanized via $\mathrm{CO}_{2}$ asphyxiation, kidneys dissected and fixed with $4 \%$ PFA. Kidneys were then embedded into paraffin, $5 \mu \mathrm{m}$ sections cut, deparaffined with xylene and rehydrated in decreasing amounts of alcohol. Sections were blocked with 5\% BSA, 0.1\% goat serum, in TBST for one hour at room temperature. Sections were incubated with the following primary antibodies for two hours at room temperature in blocking buffer: mouse anti NFKB p65 (Transduction Laboratories, BdBiosciences, San Jose, CA, USA, Cat. N67620050) (1:10 dilution), rabbit anti-phospho-IKK $\alpha / \beta$ (Cell Signaling, Cat. 2078) (1:10 dilution), rabbit anti MIF
(Santa Cruz, Cat. sc-20121) (1:50 dilution), rabbit antiphospho-p65 (Cell Signaling, Cat. 3033) (1:50 dilution). After washing with PBS, the sections were then incubated for 30 minutes at room temperature with goat anti-mouse Alexa fluor 488 (Molecular Probes, Carslbad, CA, USA, Cat. A-11029) (1:1000) or goat anti rabbit Alexa fluor 488 (Molecular Probes, Cat. A-11008) (1:1000) in blocking buffer. Dual primary antibody staining was performed in sequential fashion. The cells were then washed with PBS, stained with DAPI and stored at $4^{\circ} \mathrm{C}$. Images were taken on a Zeiss Axiovert 200 fluorescent microscope and pseudo colored with MetaMorph software version 6.1 (Universal Imaging Corporation, Sunnyvale, CA, USA).

\section{NRAGE:Cherry HoxB7 transgenic mice}

Creation and maintenance of transgenic mice is as previously described [11]. Protocols and procedures were approved by MMCRI's IACUC; under the title of Numb/NRAGE in tumor Metastasis, project number 0801.

\section{Abbreviations}

BMP: bone morphogenic protein; GFP: green fluorescent protein; MIF macrophage migration inhibitory factor; NRAGE: neurotrophin receptorinteracting MAGE protein; TGF- $\beta$ : transforming growth factor $\beta$.

\section{Acknowledgements}

We would like to acknowledge the Histology Core at MMCRI for providing us with the tissue sections used in this study. We would also like to thank the reviewers assigned to this manuscript for their time and effort during the submission process. Funding for this manuscript was provided by Dr. Joseph Verdi, NIH grant number 5R01NS055304-03 and a NIH COBRE P20RR018789 in Stem Cell Biology and Regenerative Medicine awarded to Maine Medical Center (Portland, ME, USA). Additional funding was provided by the Graduate School of Biomedical Sciences and the Functional Genomics IGERT Program at the University of Maine.

\section{Author details}

${ }^{1}$ Maine Medical Center Research Institute, Center for Molecular Medicine, 81 Research Drive, Scarborough, Maine 04074, USA. ${ }^{2}$ Graduate School of Biomedical Sciences, The University of Maine at Orono, 267A Engineering and Science Research Building, Orono, Maine, 04469 USA. ${ }^{3}$ Functional Genomics IGERT Program, 263 Engineering and Research Science Building, The University of Maine at Orono, Orono, Maine, 04469 USA.

\section{Authors' contributions}

NM designed, performed or assisted on all experiments. JR constructed the NRAGE plasmid used and AK established the NRAGE stable line. TA assisted with mouse dissections and histology slides. All authors provided a detailed examination and critique of the manuscript prior to submission.

\section{Authors' information}

NM is a PhD candidate in cellular biology with a focus in developmental immunology. JR is a PhD candidate in functional genomics with a focus in neural apoptosis. JV is the primary investigator whose research is focused on neural development.

\section{Competing interests}

The authors declare that they have no competing interests.

Received: 14 August 2009

Accepted: 25 January 2010 Published: 25 January 2010 


\section{References}

1. Heldin $\mathrm{CH}$, Miyazono $\mathrm{K}$, ten Dijke P: TGF-b signalling from cell membrane to nucleus through SMAD proteins. Nature 1997, 390:465-471.

2. Hofer-Warbinek R, Schmid JA, Stehlik C, Binder BR, Lipp J, de Martin R: Activation of NF-kappa B by XIAP, the $X$ chromosome-linked inhibitor of apoptosis, in endothelial cells involves TAK1. J Biol Chem 2000, 275:22064-22068.

3. Lu M, Lin SC, Huang Y, Kang YJ, Rich R, Lo YC, Myszka D, Han J, Wu H: XIAP induces NF-kappaB activation via the BIR1/TAB1 interaction and BIR1 dimerization. Mol Cell Biol 2007, 26:689-702.

4. Carmody RJ, Chen YH: Nuclear factor-kappaB: activation and regulation during toll-like receptor signaling. Cell Mol Immunol 2007, 4:21-41.

5. Hiscott J, Nguyen TL, Arguello M, Nakhaei P, Paz S: Manipulation of the nuclear factor-kappaB pathway and the innate immune response by viruses. Oncogene 2006, 25:6844-6867.

6. Shibuya H, Yamaguchi K, Shirakabe K, Tonegawa A, Gotoh Y, Ueno N, Irie K, Nishida E, Matsumoto K: TAB1: an activator of the TAK1 MAPKKK in TGFb signal transduction. Science 1996, 272:1179-1182.

7. Shibuya H, Iwata H, Masuyama N, Gotoh Y, Yamaguchi K, Irie K, Matsumoto K, Nishida E, Ueno N: Role of TAK1 and TAB1 in BMP signaling in early Xenopus development. EMBO J 1998, 17:1019-1028.

8. Yamaguchi K, Nagai S, Ninomiya-Tsuji J, Nishita M, Tamai K, Irie K, Ueno N, Nishida E, Shibuya H, Matsumoto K: XIAP, a cellular member of the inhibitor of apoptosis protein family, links the receptors to TAB1-TAK1 in the BMP signaling pathway. EMBO J 1999, 18:179-187.

9. Jordan BW, Dinev D, LeMellay V, Troppmair J, Gotz R, Wixler L, Sendtner M, Ludwig S, Rapp UR: Neurotrophin receptor-interacting mage homologue is an inducible inhibitor of apoptosis protein-interacting protein that augments cell death. J Biol Chem 2001, 276:39985-39989.

10. Kendall SE, Battelli C, Irwin S, Mitchell JG, Glackin CA, Verdi JM: NRAGE mediates p38 activation and neural progenitor apoptosis via the bone morphogenetic protein signaling cascade. Mol Cell Biol 2005, 25:7711-7724.

11. Nikopoulos George, Martins, Joao, Adams, Tamara, Karaczyn, Aldona Adams, Derek, Vary, Calvin, Verdi, Joseph : NRAGE: A Potential Rheostat During Branching Morphogenesis. Mechanisms of Development 2009 .

12. Sommer $L$, Rao M: Neural stem cells and regulation of cell number. Prog Neurobiol 2002, 66:1-18

13. Blaschke AJ, Weiner JA, Chun J: Programmed cell death is a universal feature of embryonic and postnatal neuroproliferative regions throughout the central nervous system. J Comp Neurol 1998, 396:39-50.

14. Haydar TF, Kuan CY, Flavell RA, Rakic P: The role of cell death in regulating the size and shape of the mammalian forebrain. Cerebral Cortex 1999, 9:621-626.

15. Bruno T, Lezzi S, De Nicola F, Di Padova M, Desantis A, Scarsella M, Di Certo MG, Leonetti C, Floridi A, Passananti C, Fanciulli M: Che-1 activates XIAP expression in response to DNA damage. Cell Death Differ 2008, 15:515-520.

16. Di Certo MG, Corbin N, Bruno T, lezzi S, De Nicola F, Desantis A, Ciotti MT, Mattei E, Floridi A, Fanciulli M, Passananti C: NRAGE associates with the anti-apoptotic factor Che-1 and regulates its degradation to induce cell death. J Cell Sci 2007, 120:1852-1858.

17. Kelly MG, Alvero AB, Chen R, Silasi DA, Abrahams VM, Chan S, Visintin I, Rutherford T, Mor G: TLR-4 signaling promotes tumor growth and paclitaxel chemoresistance in ovarian cancer. Cancer Res 2006 66:3859-3868.

18. Veillat $\mathrm{V}$, Lavoie $\mathrm{CH}$, Metz CN, Roger $\mathrm{T}$, Labelle $\mathrm{Y}$, Akoum A: Involvement of nuclear factor-kappaB in macrophage migration inhibitory factor gene transcription up-regulation induced by interleukin- 1 beta in ectopic endometrial cells. Fertil Steril 2009, 91:2148-2156.

19. Calandra T, Roger T: Macrophage migration inhibitory factor: a regulator of innate immunity. Nat Rev Immunol 2003, 3:791-800.

20. Kleemann R, Hausser A, Geiger G, Mischke R, Burger-Kentischer A, Flieger O, Johannes FJ, Roger T, Calandra T, Kapurniotu A, Grell M, Finkelmeier D, Brunner $\mathrm{H}$, Bernhagen J: Intracellular action of the cytokine MIF to modulate AP-1 activity and the cell cycle through Jab1. Nature 2000, 408:211-216.

21. Hudson JD, Shoaibi MA, Maestro R, Carnero A, Hannon GJ, Beach DH: A proinflammatory cytokine inhibits p53 tumor suppressor activity. J Exp Med 1999, 190:1375-1382.
22. Jung $\mathrm{H}$, Seong $\mathrm{HA}, \mathrm{Ha} \mathrm{H}$ : Critical role of cysteine residue 81 of macrophage migration inhibitory factor (MIF) in MIF-induced inhibition of p53 activity. J Biol Chem 2008, 83:20383-20396.

23. Deng H, Makizumi R, Ravikumar TS, Dong H, Yang W, Yang WL: Bone morphogenetic protein-4 is overexpressed in colonic adenocarcinomas and promotes migration and invasion of HCT116 cells. Exp Cell Res 2007, 313:1033-1044.

24. Feeley BT, Krenek L, Liu N, Hsu WK, Gamradt SC, Schwarz EM, Huard J, Lieberman JR: Overexpression of noggin inhibits BMP-mediated growth of osteolytic prostate cancer lesions. Bone 2006, 38:154-166.

25. Gordon KJ, Kirkbride KC, How T, Blobe GC: Bone Morphogenetic Proteins Induce Pancreatic Cancer Cell Invasiveness through a Smad1-dependent Mechanism that Involves Matrix Metalloproteinase Protein-2. Carcinogenesis 2008

26. Montesano R, Sarkozi R, Schramek H: Bone morphogenetic protein-4 strongly potentiates growth factor-induced proliferation of mammary epithelial cells. Biochem Biophys Res Commun 2008, 34:164-168.

27. Bach JP, Rinn B, Meyer B, Dodel R, Bacher M: Role of MIF in inflammation and tumorigenesis. Oncology 2008, 75:127-133.

28. Camlica H, Duranyildiz D, Oguz H, Oral EN, Yasasever V: The diagnostic value of macrophage migration inhibitory factor (MIF) in gastric cancer. Pathol Oncol Res 2008, 14:79-83.

29. McClelland M, Zhao L, Carskadon S, Arenberg D: Expression of CD74, the receptor for macrophage migration inhibitory factor, in non-small cell lung cancer. Am J Pathol 2009, 174:638-646.

30. Xu X, Wang B, Ye C, Yao C, Lin Y, Huang X, Zhang Y, Wang S: Overexpression of macrophage migration inhibitory factor induces angiogenesis in human breast cancer. Cancer Lett 2008, 261:147-157.

31. Cain JE, Hartwig S, Bertram JF, Rosenblum ND: Bone morphogenetic protein signaling in the developing kidney: present and future. Differentiation 2008, 76:831-842.

32. Cain JE, Nion T, Jeulin D, Bertram JF: Exogenous BMP-4 amplifies asymmetric ureteric branching in the developing mouse kidney in vitro. Kidney Int 2005, 67:420-431.

33. Yanagita M: Balance between bone morphogenetic proteins and thei antagonists in kidney injury. Ther Apher Dial 2007, 11(Suppl 1):S38-43.

34. Blank U, Brown A, Adams DC, Karolak MJ, Oxburgh L: BMP7 promotes proliferation of nephron progenitor cells via a JNK-dependent mechanism. Development 2009, 136:3557-3566.

35. Oxburgh L, Dudley AT, Godin RE, Koonce CH, Islam A, Anderson DC, Bikoff EK, Robertson EJ: BMP4 substitutes for loss of BMP7 during kidney development. Dev Biol 2005, 286:637-646.

36. Imamura K, Nishihira J, Suzuki M, Yasuda K, Sasaki S, Kusunoki Y, Tochimaru $H$, Takekoshi $Y$ : Identification and immunohistochemical localization of macrophage migration inhibitory factor in human kidney. Biochem Mol Biol Int 1996, 40:1233-1242

37. Bruchfeld A, Carrero JJ, Qureshi AR, Lindholm B, Barany P, Heimburger O, $\mathrm{Hu}$ M, Lin X, Stenvinkel P, Miller EJ: Elevated serum macrophage migration inhibitory factor (MIF) concentrations in chronic kidney disease (CKD) are associated with markers of oxidative stress and endothelial activation. Mol Med 2009, 15:70-75.

38. Lan HY, Bacher M, Yang N, Mu W, Nikolic-Paterson DJ, Metz C, Meinhardt A Bucala R, Atkins RC: The pathogenic role of macrophage migration inhibitory factor in immunologically induced kidney disease in the rat. $J$ Exp Med 1997, 185:1455-1465.

39. Lan HY, Mu W, Yang N, Meinhardt A, Nikolic-Paterson DJ, Ng YY, Bacher M, Atkins RC, Bucala R: De Novo renal expression of macrophage migration inhibitory factor during the development of rat crescentic glomerulonephritis. Am J Pathol 1996, 149:1119-1127.

40. Sasaki S, Nishihira J, Ishibashi T, Yamasaki Y, Obikane K, Echigoya M, Sado Y, Ninomiya $Y$, Kobayashi K: Transgene of MIF induces podocyte injury and progressive mesangial sclerosis in the mouse kidney. Kidney Int 2004, 65:469-481.

41. Furuta Y, Piston DW, Hogan BL: Bone morphogenetic proteins (BMPs) as regulators of dorsal forebrain development. Development 1997. 124:2203-2212.

42. Li W, Cogswell CA, LoTurco JJ: Neuronal differentiation of precursors in the neocortical ventricular zone is triggered by BMP. J Neurosci 1998, 18:8853-8862

43. Smith A, Graham A: Restricting Bmp-4 mediated apoptosis in hindbrain neural crest. Dev Dyn 2001, 220:276-283. 
44. Kendall SE, Battelli C, Irwin S, Mitchell JG, Glackin CA, Verdi JM: NRAGE mediates p38 activation and neural progenitor apoptosis via the bone morphogenetic protein signaling cascade. Mol Cell Biol 2005, 25:7711-7724

45. Ito K, Yoshiura Y, Ototake M, Nakanishi T: Macrophage migration inhibitory factor (MIF) is essential for development of zebrafish, Danio rerio. Dev Comp Immunol 2008, 32:664-672.

46. Kobayashi S, Sotamura K, Levsky JM, Sreenath T, Wistow GJ, Semba I, Shum L, Slavkin HC, Kulkarni AB: Expression pattern of macrophage migration inhibitory factor during embryogenesis. Mech Dev 1999, 84:153-156.

47. Suzuki H, Nishihira J, Koyama $Y$, Kanagawa $H$ : The role of macrophage migration inhibitory factor in pregnancy and development of murine embryos. Biochem Mol 1996, 38:409-416.

48. Suzuki M, Takamura Y, Maéno M, Tochinai S, lyaguchi D, Tanaka I, Nishihira J, Ishibashi T: Xenopus laevis macrophage migration inhibitory factor is essential for axis formation and neural development. J Biol Chem 2004, 279:21406-21414.

doi:10.1186/1741-7007-8-7

Cite this article as: Matluk et al:: A role for NRAGE in NF- $\kappa \mathrm{B}$ activation through the non-canonical BMP pathway. BMC Biology 2010 8:7.

\section{Submit your next manuscript to BioMed Central} and take full advantage of:

- Convenient online submission

- Thorough peer review

- No space constraints or color figure charges

- Immediate publication on acceptance

- Inclusion in PubMed, CAS, Scopus and Google Scholar

- Research which is freely available for redistribution

Submit your manuscript at www.biomedcentral.com/submit 